\title{
> Produção em tempos de isolamento
}

\author{
$>$ Production in times of isolation
}

por Davi Alexandre Tomm

Doutorando em Letras na UFRGS, na linha de pesquisa Teoria, Crítica e Comparatismo. Bolsista CAPES. E-mail: tomm.davi@gmail.com. ORCID: 0000-0001-5713-0701.

\section{por Guilherme Mautone}

Doutorando em Filosofia na UFRGS, com pesquisa em Filosofia da Arte e Estética sobre a questão das definições de arte, intencionalismo, contextualismo e arte contemporânea. Bolsista CAPES. E-mail: guimautone@gmail.com. ORCID: 0000-0001-8623-6230.

\section{por Lauro Iglesias Quadrado}

Professor Adjunto do Instituto de Letras da Universidade Federal da Bahia. Doutor em Letras - Literaturas de Língua Inglesa, pela UFRGS. E-mail: lauroiq@gmail.com. ORCID: 0000-0002-8272-0073.

\section{por Patrícia Cristine Hoff}

Professora no Instituto Federal Sul-rio-grandense. Doutoranda em Letras na UFRGS, na linha de pesquisa Teoria, Crítica e Comparatismo. E-mail: patriciacristine.hoff@gmail.com. ORCID: 0000-0001-9910-7892.

\section{por Paula Trusz}

Doutoranda em Artes Visuais junto ao PPGAV/UFRGS, na área de História, Teoria e Crítica. E-mail: paulatrusz@gmail.com. ORCID: 0000-0002-5700-1245.

Em tempos de polarização política, rompantes autoritários e em meio à maior crise sanitária dos últimos anos, chegamos à primeira edição do segundo ano da Revista PHILIA | Filosofia, Literatura \& Arte. Neste número, produzido a partir de temática livre lançada no final de 2019, mantém-se o 
caráter interdisciplinar, trazendo artigos de qualidade acadêmica e que, por vezes, amalgamam em suas temáticas as três áreas do conhecimento presentes no escopo da revista.

O contentamento de finalizarmos um processo longo e detalhado como a editoração de uma revista acadêmica, que mobiliza tantas pessoas e afetos, não esconde, porém, uma tarefa que é cada vez mais árdua em solo brasileiro: a pesquisa acadêmica. Dependente dos parcos e cada vez mais escassos recursos federais, a produção e a divulgação científicas enfrentam um de seus piores momentos a nível de investimento. Nesse sentido, manter-se instigado e produtivo ganha roupagem de resistência, quando defender a óbvia importância da academia passa a ser tarefa quase cotidiana.

Frente a essas dificuldades, que, infelizmente, já não soam como novidade, torna-se impossível não comentar o inesperado contexto de isolamento social em escala mundial que estamos vivendo em decorrência da pandemia de Covid-19. Este cenário, que ganha ares de um roteiro distópico, foi capaz de colocar em suspenso muitos dos laços que mantinham a estrutura social em funcionamento. De uma hora para outra, a economia passou a reavaliar seus métodos produtivos, o Estado precisou amparar a nível de urgência aqueles e aquelas que se viram sem renda, as universidades e escolas tiveram que reinventar formas de manter em andamento o ano letivo, e as famílias aprenderam que afastamento tornou-se sinônimo de cuidado.

À preocupação decorrente do cenário de isolamento social soma-se a discussão a respeito da saúde mental da população. Manter-se fisicamente afastado das pessoas em tempos de hiperconexão e compartilhamento de 
experiências trouxe mais uma camada de suspeita ao - já não tão festejado desenvolvimento tecnológico. Com isso, nos vemos, mais do que nunca, enquanto sujeitos ciborgues ${ }^{1}$. Até quando o virtualizado corpo-imagem substitui a presença de um corpo-matéria? O que fazer quando, muitas vezes, a janela para o mundo exterior e o contato com os outros se dá quase que exclusivamente via telas luminosas?

Essas questões suscitam novos debates acerca da já citada resistência da pesquisa acadêmica, que, agora, se reforça enquanto trabalho individual e solitário. Ou, melhor, talvez essa situação de isolamento social e fechamento das instituições de ensino traga à tona justamente a necessidade do diálogo, da circulação e das trocas na produção realizada dentro da academia. Dentro desse complexo contexto que se descortina, ao olharmos para o início do ano, quando ainda vivíamos sob outra ordem de existência, e quando ainda não tínhamos ideia do que estava por vir, uma dúvida - grave e pertinente - paira no ar: quais serão as novas normalidades ao fim da pandemia?

Mesmo inseridos nesse clima de incertezas, apresentamos agora o resultado de seis meses de trabalho, que resultaram no 1 으 número do 2 o volume da Revista PHILIA | Filosofia, Literatura \& Arte. Fazem parte desta edição vinte e três artigos, uma resenha, dois ensaios visuais e uma tradução.

Iniciando a apresentação da seção de artigos, temos Elementos para a interpretação de Tempo de Espalhar Pedras, de Estevão Azevedo, escrito por Ana Laura Malmaceda. O trabalho traz uma análise do romance Tempo de

\footnotetext{
${ }^{1}$ Donna Haraway, Manifesto Ciborgue. In Tomaz Tadeu, Antropologia do ciborgue. As vertigens do pós-humano, 2016
} 
Espalhar Pedras (2014) a partir de uma perspectiva estilística, tecendo relações com uma tradição do romance regionalista brasileiro. No entanto, o artigo vai além, procurando perceber as especificidades da narrativa frente ao contexto literário contemporâneo nacional.

Já um questionamento pessimista sobre o futuro e o progresso tecnológico e científico está presente no artigo Pessimismo e monstruosidade: uma análise comparativa entre Frankenstein e Jogos vorazes, de Andressa Carolina dos Santos Benedito e Fernanda Martinez Tarran. No texto, é investigada a ideia de monstruosidade na trilogia Jogos Vorazes, tendo Frankenstein como ponto de partida fundamental para a construção do que vem a ser um monstro para a cultura ocidental.

Antônio José Nascimento examina os escritos de Marcuse, destacando seu protagonismo no desenvolvimento de um pensamento que busca compreender as relações produtivistas da tecnociência moderna. Além disso, seu artigo Metafísica e racionalidade tecnocientífica em Marcuse propõe um breve cotejamento entre a abordagem teórica de Heidegger sobre a consumação da metafísica na técnica e o extrapolar da irracionalidade metafísica, tal como proposto por Marcuse.

A inquietação frente à imobilidade e ao sufocamento das metrópoles contemporâneas serviu de disparador para o desenvolvimento do artigo de Artur Dória Mota, Há cidade por vir? Pensamentos para além da metrópole. O autor investiga a noção atual de cidade, a qual teria origem em dois conceitos: polis e civitas. A partir disso, indaga-se a respeito de outras possibilidades de ser e habitar as metrópoles. 
Os escritos de Charles Baudelaire são o objeto de estudo do artigo de Augusto Darde, Correspondências e sinestesias quando Baudelaire aprecia Delacroix. Nele, o autor busca perceber as relações entre a produção poética baudelairiana, com a obra Les Fleurs du mal (1857), e suas críticas de arte sobre as obras pictóricas de Eugène Delacroix, dando a ver as imbricações de sua linguagem poética em suas duas vertentes de trabalho.

Carolina Montebelo Barcelos, em 0 diálogo do contemporâneo com o passado: uma discussão teórico-estética, traz uma discussão acerca do conceito de contemporâneo como um diálogo com o passado, servindo-se, para isso, dos escritos de Giorgio Agamben e Georges Didi-Huberman. A discussão se complementa a partir de uma abordagem via campo das artes, com Boris Groys, Miwon Kwon e Richard Mayer, para, por fim, aproximar-se da produção artística brasileira, a partir da perspectiva do contemporâneo.

No artigo Em busca de um teatro perdido: notas sobre $\mathbf{O}$ tribofe, de Arthur Azevedo, Diego dos Santos Reis empreende um estudo acerca do teatro de revista produzido no Brasil no ano de 1891. A partir disso, Reis examina de que forma a recente República brasileira se faz presente na peça $O$ tribofe, percebendo o teatro de revista como uma forma de espaço de crítica ao contexto político do período.

A obra Madame Bovary é objeto de estudo de Hêmille Raquel Santos Perdigão no artigo "Sobre essa grande esteira rolante que são as páginas de Flaubert": procurando os motivos nos quadros de Madame Bovary. Sua abordagem parte do confronto entre duas visões diferentes a respeito da citada obra literária: enquanto Nabokov a percebe enquanto pseudossubjetiva, 
Auerbach a percebe como objetiva. A fim de corroborar com a discussão, é feita uma aproximação entre Madame Bovary e algumas produções pictóricas que se aproximam do estilo do romance.

Deleuze e Guattari são convocados para a análise de Karine Mathias Döll sobre a obra literária Mar azul (2012), de Paloma Vidal, no artigo Por uma esquizoanálise das narrativas de estupro: uma leitura de Mar azul (2012) de Paloma Vidal. Döll ancora-se em conceitos dos filósofos, como desterritorialização, reterritorialização, rostidade, plano de imanência e corpo sem órgãos, a fim de trazer questões caras aos estudos de gênero, como as noções de mulher-corpo/mulher-mente, "cultura do estupro" e estratificações epistemológicas.

Leandro Souza Borges Silva desenvolve em 0 amor que não ousa dizer seu nome: notações homoculturais em 0 retrato de Dorian Gray, de Oscar Wilde uma argumentação buscando perceber sutilezas homoafetivas no romance de 1890. Para isso, fundamenta-se nos escritos de Leonor Arfuch, Eliane Cristine Raab Pires, Daniel Salvatore Schiffer, Michel Foucault e Mário Cesar Lugarinho.

\section{Um teto para a crítica genética: a teoria e o pesquisador da gênese,} artigo de Luana Maria Andretta, traz uma discussão sobre a crítica genética, que se dedica a estudar manuscritos literários. Pela resistência que a crítica genética ainda enfrenta no campo literário, Andretta propõe um levantamento bibliográfico em que discute três hipóteses para este possível afastamento. Além de tentar compreendê-los, a autora busca sistematizar contribuições da crítica genética na área de conhecimento. 
Mariana Fortes Maia investiga na obra Campo Geral (1964), de Guimarães Rosa, alguns relatos de atitudes diante da morte a partir do ponto de vista infantil, conforme trazidos por Miguilin e Dito. Dessa forma, o artigo Estórias de crianças que não têm fim: a poetização da morte através do ponto de vista infantil em "Campo Geral", de Guimarães Rosa busca perceber a morte como parte elementar da vida, refutando-lhe um possível caráter lúgubre.

Marloren Lopes Miranda, no artigo Escritas de mulheres: uma investigação metodológica, propõe um debate a respeito da natureza dos textos filosóficos, problematizando seu local de produção e circulação, muitas vezes restrito ao ambiente acadêmico, e, em função disso, limitado a certos padrões científicos. Essa padronização traria em si uma parcialidade de abordagens e métodos, muitas vezes ligados aos olhares e discursos do homem branco.

Os conceitos de cópia e simulacro, conforme desenvolvidos por Platão em A República e depois revisitados por Gilles Deleuze em Platão e o Simulacro, são o ponto de partida de Milene Paixão Silva em seu artigo, Cópia e simulacro: potencialidades da representação da doméstica em Carolina Maria de Jesus. A autora analisa os escritos Diário de Bitita e A Empregada, de Carolina Maria de Jesus, objetivando compreender em que medida as produções literárias com ênfase autobiográfica dialogam com os conceitos de cópia e simulacro.

Egon Schiele (1890-1918), artista austríaco, é o protagonista do conto A santa de Schöneberg, de Rubem Fonseca, objeto de estudo de Murilo Eduardo dos Reis no artigo Rubem Fonseca: da moldura à ekphrasis. Nele, Reis busca compreender como o desenvolvimento da trama é influenciado pelos conceitos de moldura e ekphrasis. 
No artigo Distopias e espaços sociais na produção artística contemporânea: espaços heterotópicos, heterocrônicos e heteróclitos, Paola Mayer Fabres investiga as noções de espaço e território na contemporaneidade artística. Para isso, serve-se do conceito de "espaço heterotópico", de Michel Foucault. O estudo de Fabres observa uma mudança na lógica utópica moderna de busca por "espaços ideais", para o interesse em "espaços reais". Para isso, analisa as obras de Irene Serra, artista argentina participante da residência Comunitária, e Maria Helena Bernardes, artista brasileira que realizou a obra Vaga em campo de rejeito em Arroio dos Ratos/RS.

Paulo Alexandre e Castro, no artigo Fenomenologia e Estética Comparativa: antropometrias e (in)visibilidades nos Corpus. Para um diálogo entre Yves Klein e Merleau-Ponty, propõe uma reflexão comparativa, através dos aspectos estéticos e fenomenológicos, entre a produção artística de Yves Klein e os escritos de Merleau-Ponty. Para isso, estabelece uma interlocução entre ambos a partir dos conceitos de visibilidade, corpo e mundo.

No artigo Sobre o conceito de consciência em Heidegger, Rafael Ribeiro Almeida e Fabíola Menezes Araújo investigam a noção de consciência (Gewissen), conforme esta aparece, em especial, no segundo capítulo da obra Ser e Tempo, e enquanto fenômeno existencial e originário.

A partir da leitura de György Lukács e Mikhail Bakhtin, Thaís Cristina da Silva investiga questões relacionadas aos conceitos de romance e epopeia a partir de uma análise da obra Levantado do chão, de José Saramago. Seu artigo A insurreição em Levantado do chão: da ordem social às vicissitudes do 
romance dá ênfase aos processos de reescrita da história de Portugal, conforme empreendida por Saramago na citada obra literária.

\section{A imagem da morte: arte contemporânea e produção de sentidos,} artigo de Vinícius Borges Figueiredo, empreende uma reflexão sobre o meio fotográfico, com o amparo dos escritos de Roland Barthes, Philippe Dubois e Vilém Flusser, a partir das relações entre corpo, representação e morte. Para isso, Figueiredo debruça-se à análise dos trabalhos artísticos de Rosângela Rennó, Christian Boltanski e Udessa Hendeles.

Já o artigo Por dentro dos caminhos de "S.", de J.J. Abrams e Doug Dorst: as ações de lançamento da edição brasileira, de Vitória Ferreira Doretto, traça e investiga os meandros dos processos editoriais dos livros, desde a revisão, diagramação, impressão e distribuição dos exemplares, tendo como objeto de estudo o livro "S", de autoria de J.J. Abrams e Doug Dorst. O estudo realizado foca na campanha de marketing empreendida pela editora Intrínseca, e acompanha o seu lançamento tanto no Brasil quanto nos Estados Unidos.

Para encerrar a seção de artigos, temos o trabalho Filosofia negativa, filosofia positiva: a crítica de Schelling ao idealismo, de Wagner Félix. Nele, é analisada a crítica de Schelling à filosofia idealista na busca pelo entendimento da filosofia positiva do filósofo em seus trabalhos posteriores.

Na seção de resenhas, temos $\mathbf{A}$ incompreensão de Bacurau, de Natália Acurcio Cardoso. A autora debruça-se sobre o filme Bacurau (2019), dirigido por Kleber Mendonça Filho e Juliano Dornelles, examinando a relação da cidade e seus habitantes com os estrangeiros que lá chegam. Além disso, Cardoso coloca 
em diálogo duas opiniões recorrentes sobre a produção audiovisual: a de que Bacurau seria uma cidade utópica e atípica, e de que justamente esse fator seria um ponto negativo do filme. A partir de tais opiniões, a autora constrói sua argumentação, buscando uma terceira via de acesso à produção.

Na seção de ensaios visuais, apresentamos, pela primeira vez, mais de um ensaio. O primeiro deles, Como construir uma vista, de Carlos Donaduzzi, explora, através da cianotipia, uma reflexão sobre o desaparecimento de horizontes, buscando uma percepção do mundo sem a mediação de telas luminosas.

O ensaio visual de Mayra Redin é o que ilustra a atual edição da Revista PHILIA | Filosofia, Literatura \& Arte. Chamado Aterro, parte de uma ação da artista na floresta da Ecovila Terra Una, com participação da professora Fernanda Lenzi e das crianças da escola da Ecovila. O trabalho justapõe telhas de barro e enciclopédias, como se um fizesse a sustentação do outro, e foi deixado às vicissitudes naturais e dos habitantes do local.

Por fim, na seção de traduções, Luiz Roberto Lins Almeida e Maria Liz Benitez Almeida trazem a tradução de uma seleção de microcontos de Mario Halley Mora (1926-2003), escritor e jornalista paraguaio ainda pouco conhecido no Brasil. O escritor, embora se destaque como dramaturgo, circulava por diversos gêneros literários, incluindo poemas, contos, romances, letras de música, roteiros de cinema e tirinhas de jornal.

Ao final, aproveitamos a oportunidade deste editorial para agradecer imensamente a todos e todas que confiaram suas produções à Revista PHILIA | 
Filosofia, Literatura \& Arte, bem como aos colaboradores e colaboradoras que fizeram parte de cada etapa de trabalho. Aos assistentes editoriais Liana Schedler, André Luís de Souza Lima, Deborah Mondadori Simionato, Lucas Cyrino, Gabriela Traple Wieczorek e Luciane Bucksdricker. Aos revisores e revisoras Adriana Viegas Caterina, Cláudia Fernanda Pavan, Denise de Quintana Estacio, Fernanda Nunes Menegotto, Francelle Machado Viegas, Helen Ribeiro Nunes, Joanne de Bittencourt Fraga, Leonardo Foschiera de Mesquita, Lucas Meireles Tcacenco e Sara Luiza Hoff. E também aos avaliadores e avaliadoras dos artigos.

Esperamos que essa edição da Revista PHILIA | Filosofia, Literatura \& Arte traga férteis discussões aos leitores e leitoras.

\section{Referências}

HARAWAY, Donna. Manifesto Ciborgue. In TADEU, Tomaz. Antropologia do ciborgue. As vertigens do pós-humano. $2^{\mathrm{a}}$ ed., $2^{\mathrm{a}}$ reimp., Belo Horizonte: Autêntica Editora, 2016.

\section{Referência para citação deste editorial}

TOMM, D. A.; MAUTONE, G.; QUADRADO, L. I.; HOFF, P. C.; TRUSZ, P. Editorial - Produção em tempos de isolamento. Revista PHILIA | Filosofia, Literatura \& Arte, Porto Alegre, volume 2, número 1, p. x - xx , junho de 2020. 